\title{
Pain Relief by Analgesic Eardrops: Paradigm Shift in the Treatment of Acute Otitis Media?
}

\author{
Author \\ Olaf Michel
}

\section{Affiliation}

Universitair Ziekenhuis - Vrije Universiteit Brussel UZ-VUB, Belgium

Key words

Local anesthetic treatment; acute otitis media

received 11.02 .2020

accepted 25.04.2020

published online $\quad 07.06 .2021$

\section{Bibliography \\ Drug Res 2021; 71: 363-371 \\ DOI 10.1055/a-1494-3087 \\ ISSN 2194-9379}

(C) 2021. Thieme. All rights reserved.

Georg Thieme Verlag KG, Rüdigerstraße 14,

70469 Stuttgart, Germany

\section{Correspondence}

Prof. Dr. med. O. Michel

Afdelingshoofd dienst KNO, Universitair Ziekenhuis - Vrije

Universiteit Brussel UZ-VUB

Laarbeeklaan 101

BE-1090 Brussel

Belgium

Tel.: + 32-2-477 6889/6888, Fax: + 32-2-477 6880

OMichel@uzbrussel.be

\begin{abstract}
Acute otitis media is a common middle ear infection in children with the predominant symptoms of hearing impairment and pain. If antibiotics are given, they need time to have an effect on the inflammation, so the focus is on pain control. For pain management local anesthetics have the advantage of lesser systemic side effects but are still subject to scrutiny. In this review the literature between 2000 and 2020 was systematically searched for investigating studies and recommendation in guidelines against the background of the mode of action. 11 clinical studies, 2 guidelines and 5 reports resp. reviews could be identified. Contraindications and side effects were not found in these studies. The analgesic ear drops showed in placebocontrolled studies a relatively short duration of action when applied once but rapid onset of action. There is evidence that analgesic ear drops could provide a first-line analgesia in otitis media without systemic adverse effects such as gastrointestinal disturbance and nausea and could support an antibiotic-saving wait-and-see attitude. The review shows a change in attitude towards the recommendation to include local anesthetics ear drops in otitis media but still there is a lack in treatment protocols which go beyond a single administration. The results do not yet show a significant paradigm shift. The reviews revealed indications that a more adapted galenic preparation could give more effectiveness. Pharmaceutical research in this field should be intensified to exploit the analgesic potential of local anesthetic ear drops in acute otitis media.
\end{abstract}

\section{Introduction}

Otitis media acuta (acute otitis media, AOM, ICD-10 H66.0) typically occurs in more than $80 \%$ of children, is still present in younger adults and is rarely found in adults. A closer look at larger statistics reveals that the occurrence is highest in the age group up to 2 years [1]. One or more episodes of AOM had already occurred in $25 \%$ of children at the age of 1 year; at the age of 3 years 60 and $24 \%$ had more than 3 episodes. The highest incidence is reached at the age of 6 to 12 months of life [2].

Unilateral or bilateral otitis media is often associated with fever, but always with hearing loss and stabbing earache in up to $88 \%$ of cases [3]. They are accepted as the main symptoms in the majority of European guidelines [4]. Therefore, a clinical diagnosis can usually be made based on these three symptoms. An inspection of the tympanic membrane, which will show a bright red protruding ear- drum, and a tympanometry make the assumption a certainty if a flat effusion curve is seen.

These symptoms are not so obvious in very young patients: affected infants cry a lot, drink badly and often react with diarrhea and vomiting. In general, a possible otitis media must always be considered in the case of a sick infant, as the infant cannot indicate the location or pain as such. Further examinations such as tympanometry, pneumatic otoscopy or a hearing test are usually not tolerated in the acute stage of children because of the high pain level.

\section{Pathophysiology and disease pattern}

An anatomically and functionally unfinished Eustachian tube and an immature immune system are generally assumed to be preconditions for otitis media in children [5]. In addition, familial predisposition and numerous environmental and social factors have been identified as influencing factors, so that overall the occurrence of 
otitis media is considered multifactorial. Children with socially weak, smoking parents, for example, are much more likely to develop otitis media than children of well-off non-smokers [6].

A number of basic diseases, such as allergy, asthma, metabolic disorders and various gastric juice reflux syndromes (GERD, NERD, LPR) are also assumed to be triggering or predisposing causes [2], but have not always been confirmed in qualified studies. Larger studies with administration of proton pump inhibitors (PPI's) to remedy acid reflux have been disappointing [7]. Allergies in children with middle ear infections are also not found in greater numbers than in control groups, and conversely, the presence of an allergy is not a risk factor.

These factors initially promote the development of middle ear effusion, which then persists and is a prerequisite for otitis media acuta [8]. Conversely, in almost $50 \%$ of children, acute otitis media, after resolving with or without treatment, turns into a chronic tympanic effusion, which is usually not painful but is associated with hearing loss [9].

In the English literature, the blanched middle ear effusion is referred to as "otitis media with effusion", which partly led to the misconception in the German-speaking world that this also refers to an acute middle ear infection because of the use of the term "otitis", which actually indicates an inflammation. This has led in particular to confusion regarding the indication for antibiotic treatment. There is a consensus that a pure, bland effusion should not be treated with antibiotics, as there is no evidence for this $[10,11]$.

For a better distinction between otitis media acuta and "middle ear fluid" - a tympanic effusion - it is advised to name it "otitis media secretorica".

Histopathologically, it is important for the development of an effusion that the lining epithelial layer in the hypotympanum (caudal area of the middle ear) up to the promontory of the tympanic cavity resembles a respiratory mucosa and has many mucous glands. The secretion can assume all consistencies from thin to viscous - a phenomenon that has inspired many researches, but apart from the realization that mucins play a role [12], but there is still no real clarity about the nature of the secretion.

Acute otitis media is usually caused by a bacterial colonization of the middle ear by the ear trumpet and an effusion of the pathogens Streptococcus pneumoniae, Branhamella catarrhalis, Haemophilus influenzae und Streptococcus pyogenes [1,2]. This spectrum has been relatively constant for many decades. Usually an infection in the nasopharynx is the starting point. The spreading inflammation paralyzes the cilia of the tube, causes the epithelium to swell and thus additionally hinders the ventilation of the middle ear, which promotes an effusion.

Unfortunately, AOM is not always a purely bacterial inflammation; viruses such as Respiratory Syncytial Virus (RSV), Influenza A, Parainfluenza, Human Rhinoviruses, Adenoviruses and human Coronavirus have also been coexistently detected [2, 6, 13]. This coexistence reduces the treatment success of antibiotics. However, a viral infection cannot be distinguished from a bacterial infection in terms of pain quality.

In the sense of an accompanying mastoiditis, the mucous membranes in the mastoid process are always also affected in acute otitis media, since all air-filled spaces have a common mucous membrane cover. This is usually unproblematic, but can lead to mastoid- itis with painful protruding ears and disappearing of the bone structures.

It is rare that the external auditory canal is also affected by otitis media. Exceptions are cases of perforation of the eardrum in acute otitis media (the pain suddenly declines spontaneously) or a chronically running ear for months or years. Otherwise, the eardrum forms a long-lasting, stable barrier to the inflammation that is ongoing in the middle ear. This can also be seen from the fact that a protrusion of the highly red inflammatory eardrum is observed in acute middle ear inflammation. This is also clinical evidence of inflammation of the middle ear [5].

First, the eardrum prevents the inflamed effusion from escaping from the enclosed middle ear spaces. Pressure builds up in the middle ear and causes pain. Only when the eardrum ruptures can the purulent effusion drain away. Clinically, the pain subsides abruptly in this situation. This is the basis for the indication for an incision of the eardrum, the paracentesis [14]

From this superficial fact of a "barrier function" of the eardrum, the view has arisen that the eardrum membrane makes the application of analgesic ear drops in the case of middle ear infection appear pointless, since it is impermeable $[15,16]$. Moreover, studies have shown that the multi-layered structure of the eardrum can impede the passage of drug molecules.

\section{Pain sensation}

The innervation of the middle ear and the eardrum is very complex because it is composed of sympathetic, parasympathetic and somato-sensory parts. These have their origins in various nerve cords from the cervical plexus, the trigeminal, facial, glossopharyngeal, the vagus nerve and the cervical trunk.

The posterior part of the outer surface of the eardrum as well as the posterior wall and floor of the auditory canal is innervated by the auricularis of the vagus nerve. The external auditory canal is supplied overlappingly by the auriculo-temporal nerve and the auricular branch of the vagus nerve [17-19].

The sensory innervation of the inner surface of the eardrum and the tympanic membrane is performed by the tympanic nerve from the glossopharyngeal nerve. It originates from the ganglion petrosum and forms the tympanic plexus in the middle ear at the promontory (Jacobson's nerve). Its peripheral branches are the ramuli tympanici (mucosa of the tympanic cavity and mastoid) and the tubal branches to the Eustachian tube [20], the connection to the nasopharyngeal cavity.

For some time now, research has been conducted into the connection between the receptors in the eardrum and the Eustachian tube, since only a feedback system could explain why the pressure balance between the middle ear and the nasopharynx is caused by unconscious swallowing [21]. The chorda tympani is thought to play a role in the transmission of pain, which according to older studies may be more important than the chorda's function in taste sensation, which is usually attributed to it [22].

Whether the tympanic nerve fibers are stretch responsive fibers or pain fibers or both is not conclusively established [23, 24]. However, it is a fact that the eardrum is sensitive and can be locally anesthetized, e. g. for surgery, and that this can affect tube function [21].

In the non-inflammatory state, the eardrum, like the skin epithelium, is impenetrable to local anesthetics, although it is only 
$1 / 10 \mathrm{~mm}(100 \mu \mathrm{m})$ thick (for comparison: the cornea of the eye is 5-10 times thicker). The eardrum consists of three layers: the outer skin, which is of five-cells thick, connective tissue with collagen fibers, which gives the eardrum its structural integrity, and the inner lining of the mucous membrane, which consists of a single layer of cells [25].

In order for local anesthetics to be effective on the normal (noninflamed) eardrum, aids to loosen the epithelial layer (maceration) such as phenol [26] and menthol (obsolete in Bonain solution) or dimethyl sulfoxide (DMSO, non-ototoxic [27]) must be used to facilitate diffusion. Substances such as sodium bicarbonate and glycerol are also used to macerate the eardrum [25]. Glycerol is said to have an additional analgesic effect in otitis media due to its waterattracting (hygroscopic) property, as it is said to reduce middle ear pressure through fluid osmosis [28].

Inflammation of the eardrum, as in inflammation of the middle ear, can also lead to loosening of the epithelial structure and can also trigger changes in vascular permeability. These changes may allow local anesthetics to pass through the eardrum to the nerve pathways of the middle ear or directly affect the pain receptors in the eardrum $[29,30]$.

The $\mathrm{pH}$ plays an important role in this process, since all local anesthetics are weak electrolytes and their dissociation is influenced by the $\mathrm{pH}$ [31]. A low $\mathrm{pH}$ value, which occurs for example during inflammation, reduces the diffusion of local anesthetics [29]. The undissociated lipid-soluble base penetrates to the nerve site of action, while the dissociated water-soluble cation, as the active form, blocks the $\mathrm{Na}^{+}$- channel at the nerve. Increasing the $\mathrm{pH}$ of an anesthetic solution increases the amount of free base and thus the speed of penetration. If the $\mathrm{pH}$ value of the solution is reduced, less substance can penetrate the nerve tissue.

This connection is important, for example, in an inflamed tissue where the $\mathrm{pH}$ decreases due to acidic inflammation products. In inflamed tissue, the blood flow is also increased so that the local anesthetic is transported away more quickly and thus has a shorter duration of action than in non-inflamed tissue.

It has been pointed out that some local anesthetics, such as the cocaine hydrochloride originally used, can cause irreversible hearing loss [32]. This side effect varies with the local anesthetics; procaine, for example, has a small, reversible effect on the hearing threshold [33].

Local anesthetics can be neurotoxic, with procaine and mepivacaine being the least toxic [34]. It is not impossible that the use of topical benzocaine could cause methaemoglobinaemia as described in other applications $[35,36]$.

Another special feature is often not considered: Local anesthetics can develop antimicrobial activity [37]. However, what may initially appear to be desirable may be a disadvantage if a smear is taken from an appropriately anesthetized area to determine the bacterial spectrum and resistance.

\section{Therapy guidelines}

In the current guidelines, great controversies become obvious in the assessment of systemic or local pain treatment of acute middle ear inflammation.
- A German ENT guideline with recommendations is currently being sought in vain; only a guideline from the German College of General Practitioners and Family Physicians (DEGAM) "Ear pain" - updated 2014 - is available for general practitioners [7, 38]. In this guideline, the non-recommendation of local pain therapy is referred to a single paper in French [39], which is not available on the internet or in common databases. The evidence of this recommendation is therefore doubtful.

- Thomas et al. [14] do not recommend the administration of topical local anesthetics in a review paper and rely on a work by Hoberman and et al. [28]. However, this statement is not comprehensible, since the authors concluded that topical analgesic ear drops (here: Auralgan) were significantly superior to placebo after 30 minutes.

- The S2 guideline "Antibiotic therapy of head and neck infections" deals with acute otitis media, but completely excludes pain therapy in favor of antibiotic therapy [40].

- In the Netherlands, the Dutch College of General Practitioners (Nederlands Huisartsen Genootschap, NHG), which support evidence-based general practice, with guidelines, did not recommend local anesthetics. The committee relied to only one study of Bolt et al. [41], but found it difficult to determine whether the analgesic effect should be attributed to lidocaine ear drops or to oral analgesia which were given to all participants. Bolt et al. found it unethical to withhold simple analgesic therapy as the current standard of care for pain. The committee did not take other studies into consideration because of methodological issues and because of the use of by the Dutch FDA not approved ear drops.

- In the most recent guideline representing the view of the National Institute for Health and Care Excellence (NICE) in the United Kingdom (UK) anaesthetic ear drops were judged positively referring to the work of Foxlee et al. [42].

- The current guidelines of the American Academy of Pediatrics (AAP) and the American Academy of Family Physicians (AAFP) recommend the administration of ear drops containing benzocaine, procaine and lidocaine as an adjunct to systemic analgesia for children over 5 years of age $[8,43]$ with "limited evidence“ [44].

- The European Clinical Practical Guidelines 2020 for the treatment of acute otitis media in children do not mention pain management [4].

In the international literature on pain symptoms, there are a number of studies and Cochrane reviews [3], most of which have shown that existing studies are not suitable for demonstrating the effectiveness of locally administered analgesic ear drops on a solid and broad basis according to recognized standards because of their inadequate study design [42].

In the present study, we have investigated whether new findings have emerged with regard to the local treatment of acute otitis media with analgesic ear drops and which studies are now available. 


\section{Material and Methods}

To cover the most recent knowledge, the available literature on non-surgical treatment of AOM in the period 2000-2020 was searched in the freely accessible public databases Medline, Pubmed, the Cochrane Society and Livivivo (ZB Med Search Portal for Life Sciences) for the keywords "otitis media acuta", "acute otitis media", "middle ear infection" and "pain", "local analgesic", "otogesic". Works with surgical procedures such as paracentesis, drainage tubes or adenotomies or similar or with systemic pain management were not included.

\section{Results}

\section{Occurrence of pain}

Pain is a leading symptom of otitis media and is pathognomonic for it [44]. Therefore, pain control should be an important goal, if not the goal to avoid treatment with antibiotics.

Although the importance of pain management is consistently emphasized in all studies and reviews - with a few exceptions - only a few studies make concrete recommendations and then mostly regarding systemic pain management or antibiotic treatment [14].

In this context, it should be pointed out that it is difficult to assess pain in young children, as neither the parents nor the children provided reliable information. Thus, the sign that children touch their ears could not be correlated with the presence of otitis media [45]. This makes it difficult to conduct valid studies [28,44].

\section{Duration of pain}

The severe pain in acute otitis media (AOM) usually lasts for 24 hours at the beginning and then decreases [9]. In general, the pain lasts between 3 and 7 days (or 0,5 to 9 days following a meta-analysis [46]), with children under 2 years of age with bilateral AOM having a longer pain period than children over 2 years of age with unilateral AOM [3, 47]. In meta-analyses of non-intervention arms of randomised controlled trials, $50 \%$ of children had been free of symptoms at day 3 [46], $80 \%$ of children are pain-free without any treatment only after 2-7 days after the onset of the disease [47] and $90 \%$ by days $7-8$ [46].

\section{Antibiotics}

Hay \& et al. [48] wrote about the effectiveness of antibiotic treatment for pain (CEDAR RCT): "Although there is world-class evidence showing that antibiotics do not help, and the National Institute for Health and Care Excellence advises against their use, > 85\% of UK children with middle ear infections (acute otitis media) are prescribed an antibiotic, which is a higher percentage than for any other childhood infection. Antibiotics do not treat the child's pain and, in most cases, they do not help to treat the infection (because many ear infections are caused by viruses that do not respond to antibiotics), but they can cause side effects (such as diarrhea) and increase the problem of antibiotic resistance, which is a major public health concern."

Indications for the recommendation to give amoxicillin (40 mg/ $\mathrm{kg} \mathrm{bw/d)} \mathrm{with} \mathrm{clavulanic} \mathrm{acid} \mathrm{for} \mathrm{a} \mathrm{total} \mathrm{of} \mathrm{5-10} \mathrm{days} \mathrm{as} \mathrm{an} \mathrm{antibi-}$ otic for otitis media acuta are accepted at the presence of complications, risk factors or underlying diseases, severe otitis media with otorrhea or bilateral otitis media acuta. In case of intolerance, mac- rolides (e. g. azithromycin 10-20 mg/kg bw/d) or 2nd generation cephalosporins (e. g. cefuroximaxetil $20-30 \mathrm{mg} / \mathrm{kg}$ bw/d) are recommended.

In a prospective study published in the New England Journal of Medicine (NEJM) in children between 6 months and 2 years of age, the first two days showed a significant clinical improvement in the verum group compared to placebo [49]. This effect persisted until the 7 th day. The minimum number of children with otitis media that must be treated ("number needed to treat") for one to have an advantage was calculated to be 3.8. The side effect was predominantly diarrhea.

Despite "a deplorable lack of substantial knowledge on the issue of antibiotic therapy" in AOM, it is the most common reason for prescribing antibiotics to children. In terms of pain relief, however, the results of antibiotic treatment are generally disappointing [50].

- Indicated pain was not reduced after 24 hours by the administration of antibiotics (risk ratio (RR) 0.89; $95 \%$ confidence interval (Cl) 0.78 to 1.01 ) Nearly one-third fewer had residual pain after two to three days (RR 0.70; $95 \% \mathrm{Cl} 0.57$ to 0.86 ; number needed for treatment for an additional beneficial outcome (NNTB 20)) and fewer had pain after 4-7 days (RR 0.79; $95 \%$ Cl 0.66 to 0.95; NNTB 20) [51].

- A Cochrane review showed that antibiotics had no effect on the recurrence of AOM or on complications, including hearing loss. The same review showed no pain reduction within 24 hours and only a $30 \%$ pain reduction within 2 to 7 days of antibiotic use [47].

- Even when antibiotics are indicated, pain relief is minimal when they are administered and it takes several days before the pain stops [6].

\section{Systemic analgesics}

The current guidelines recommend the use of painkillers such as paracetamol or ibuprofen $[50,52]$. Both are COX- 1 and COX-2 inhibitors [53] and can thus trigger gastrointestinal complaints and diarrhea [54]. The administration is approved for children aged 6 months to 12 years ( $10-15 \mathrm{mg} / \mathrm{kg}$ body weight (bw) up to 4 times daily, total daily dose max. $50 \mathrm{mg} / \mathrm{kg} \mathrm{bw}$ ).

Despite explicit guideline recommendations for the use of analgesics in children with AOM $[8,14]$, a Cochrane review found no difference between ibuprofen and paracetamol for the relief of short-term earache in children with AOM, with little to very little evidence [55].

\section{Local treatment with analgesic ear drops}

Symptomatic, local, topical pain treatment in acute otitis media is desirable because side effects would be avoided as seen by systemic drug application, and pain relief could be faster and more intense and last longer than with oral analgesia. The recognition of painrelieving local ear drops in external otitis media with myringitis and the standard methods of local eardrum anesthesia for procedures such as paracentesis suggest that topical pain management in acute painful otitis media should be considered and tested in clinical trials. The following studies could be identified (in chronological order):

- A study of the efficacy of topical administration of a mixture of antipyrine, benzocaine and glycerol ("Auralgan") to 54 children 
aged 5 years to 19 years showed an improvement in pain symptoms with a statistically significant $25 \%$ reduction in pain after only 30 minutes compared to olive oil. Both groups received a single dose of acetaminophen in advance [28].

- In 103 children between 6 and 18 years of age, a double-blind randomized study was conducted on ear drops containing amethocaine, phenazone in glycerol as a local anesthetic against plant ear drops ("Oticon Otic Solution"). An oral administration of the analgesic acetaminophen was sent in advance. Statistically significant pain relief was achieved in both groups within 30 minute [56].

- In a double-blind, randomized, double-blind study of $n=171$ children aged 5 to 18 years, painkilling ear drops with amethocaine and phenazone in glycerol were tested against plant ear drops ("NHED"). Pain relief was achieved within 3 days, with a greater reduction in the group that had not been treated with antibiotics and who were treated with ear drops only [57].

- In 2004, Walson et al. published the results of a double-blind, randomized trial comparing Auralgan, Americaine and placebo ear drops in 41 children aged 0.6 years to 16 years. In the first 4 hours, Americaine and Auralgan were superior to the placebo group. The effect was levelled out 48 hours after the start of treatment [58].

- In a double-blind study, the efficacy of an aqueous $2 \%$ lignocaine ear drop compared to topical saline administration was investigated in 63 children aged $3-17$ years. The study showed a good efficacy with a significant improvement in pain values 10 minutes after application of the analgesics. No side effects were observed [41].

- In a study on the efficacy and therapeutic safety of analgesic ear drops containing procaine and phenazone in glycerol and hydroxyanisole ("Otalgan") in 428 children with otitis media aged 0 to 6 years showed a significant reduction in pain at $95.3 \%$. Tolerability was rated as good to very good in $99.8 \%$ of cases treated [59]. However, the combination of a short-acting local anesthetic and an anti-inflammatory agent is listed in the textbook "Introduction to Pharmaceutical Chemistry" as the best-known pain-relieving ear drop composition [60] .

- In 63 children aged 3-17 years, randomized aqueous 2\% lignocaine solution versus placebo (saline solution) was found to give in $52 \%$ of the treated children a $50 \%$ reduction in pain after 10 and 30 minutes compared to $25 \%$ in the placebo group. $77 \%$ had a $25 \%$ reduction after $10,81 \%$ after 20 and $90 \%$ after 30 minutes compared to resp. $44 \%, 56 \%$ and $69 \%$ in the placebo group [61].

- In a study by Hay et al. [48], a randomized, three-arm, multicenter study was carried out on children aged 1-10 years. The children received either anesthetic-analgesic ear drops with benzocaine and phenazone in glycerol ("Auralgan"), placebo (glycerol) or no ear drops. The study was stopped early for technical reasons. The consumption of antibiotics was reduced in the verum group. Due to recruitment problems in the placebo group, statistically validated results were not possible because the group was too small. However, treatment with analgesic ear drops produced the expected pain relief. No clear evidence was found whether their use reduced the consumption of antibiotics.

The following reviews and reports of the last 10 years were found:

- Thornton and colleagues recommended in their review that topical analgesics would help to relieve pain and would be better tolerated in the pediatric population [62]

- A review article for a pediatric journal stated that the empirical data on the use of local anesthetics are contradictory - the most likely benefit seems to be in older children [6].

- In a review in 2016, it was stated that although numerous high-quality studies were available, so that grade "B" recommendation level would be available, its various active ingredients and combinations had been tested, so that a particular combination could not be given preference [63].

- In the summary of a panel discussion on the treatment of otitis media, the poor evidence of previous studies was cited, but no general rejection of analgesic ear drops was expressed [64].

- The Health Technology Report (HTA) of the National Health System (NHS) examined the role of topically administered analgesic ear drops [48].

\section{Discussion}

In the treatment of acute otitis media, there is a consensus that the use of systemic antibiotics should be reduced as much as possible [Vergison et al., 2010] up to a "wait and watch" strategy [65].

However, ear pain remains a prominent symptom in the vast majority of cases, causing a high level of anxiety in the usually young patients and their parents. In general, systemic analgesia is recommended [66]. However, it is pointed out that the onset of an effect can take more than 24 hours and the pain settles only after 2-3 days, even with antibiotic treatment [65].

Nevertheless, it has been known for longer that local anesthetics in the ear provide rapid and intense pain relief. Thus, local anesthesia of the tympanic membrane has a long tradition in performing minor procedures such as tympanic membrane splinting or paracentesis $[30,67]$. It is predominantly based on empiricism. For example, the eardrum must be anesthetized for a paracentesis because the eardrum is very sensitive to pain.

Therefore, it is actually obvious to drip a local anesthetic into the ear canal even for ear pain (see $>$ Table 1). This is also accepted for external auditory canal inflammation [68-70].

Since the inflammation in acute otitis media takes place in the middle spaces on the mucous membranes located there and the tympanic membrane appears closed in the early stages of the disease, local treatment of the tympanic membrane from the outside is not considered useful - actually more from theoretical considerations than proven by scientific studies - since the tympanic membrane is considered an impermeable barrier in the opinion of many otologists $[15,16,71]$.

Even in one of the guidelines of the German Society of General and Family Medicine (DEGAM), it is stated for pain therapy of acute otitis media (AOM) that the administration of local analgesics cannot be recommended for otitis media, as they may make it difficult to assess the tympanic membrane [38]. 
- Table 1 Overview of the ingredients of some important local anesthetic ear drops with trade names that are used for local pain relief (list not complete)

\begin{tabular}{|c|c|c|c|c|c|c|}
\hline & Auralgan & Otalgan & Otigo & Otipax & Otipax & Panotile \\
\hline & US & $\mathrm{D}, \mathrm{I}, \mathrm{A}, \mathrm{CH}$ & UK & $\mathrm{CH}$ & B & $\mathrm{CH}, \mathrm{B}$ \\
\hline Benzocaine & $14 \mathrm{mg} / \mathrm{ml}$ & & & & & $20 \mathrm{mg} / 1 \mathrm{ml}$ \\
\hline Procaine-hydrochloride & & $10 \mathrm{mg} / 1 \mathrm{~g}$ & & & & \\
\hline Lidocaine-hydrochloride & & & $10 \mathrm{mg} / \mathrm{g}$ & $10 \mathrm{mg} / \mathrm{g}$ & $10 \mathrm{mg} / \mathrm{g}$ & $40 \mathrm{mg} / 1 \mathrm{ml}$ \\
\hline Phenazone/Antipyrin & 54 mg/ml & $50 \mathrm{mg} / 1 \mathrm{~g}$ & $40 \mathrm{mg} / \mathrm{g}$ & $40 \mathrm{mg} / \mathrm{g}$ & $40 \mathrm{mg} / \mathrm{g}$ & \\
\hline Polymycine-B-sulfate & & & & & & $10000 \mathrm{IE} / \mathrm{ml}$ \\
\hline Neomycine-Sulfate & & & & & & $7,5 \mathrm{mg} / \mathrm{ml}$ \\
\hline Flucortisone-acetat & & & & & & $1 \mathrm{mg} / \mathrm{ml}$ \\
\hline Glycerol & $\mathrm{x}$ & $\mathrm{x}$ & $x$ & $x$ & $x$ & $\mathrm{x}$ \\
\hline Butylhydroxyanisol & & $\mathrm{x}$ & & & & \\
\hline Sodium thiosulfate & & & $\mathrm{X}$ & & & \\
\hline Benzalkonium & & & & & & $\mathrm{X}$ \\
\hline Propylenglycol & & & & & & $\mathrm{x}$ \\
\hline \multirow[t]{2}{*}{ Ethanol } & & & $\mathrm{x}$ & $\mathrm{x}$ & $\mathrm{x}$ & \\
\hline & $\begin{array}{l}\text { Pfizer } \\
\text { Consumer } \\
\text { Healthcare }\end{array}$ & $\begin{array}{l}\text { Südmedica } \\
\text { GmbH, Vifor } \\
\text { Pharma }\end{array}$ & $\begin{array}{l}\text { Renascience } \\
\text { Pharma, United } \\
\text { Kingdom }\end{array}$ & $\begin{array}{l}\text { Zambon } \\
\text { Switzerland }\end{array}$ & Biocodex, France & $\begin{array}{l}\text { Zambon, } \\
\text { Switzerland }\end{array}$ \\
\hline
\end{tabular}

This guideline is currently under revision and has recently been extended until 01.01.2021 [7]. Here, it is additionally cited that in a few individual case studies, reduced pain and reduced local inflammatory parameters are reported, which, however, would not constitute sufficient evidence for a recommendation. In addition, a little-known work in French language is quoted, which cannot be found back in the common databases [39].

However, - as shown in the present study - a number of papers have appeared over the years dealing with the efficacy of local anesthetics on the tympanic membrane and with the passage of substances through the tympanic membrane, suggesting a different point of view $[30,72]$.

Yang et al. [73] have investigated the efficacy of buvicaine and tetrodotoxin in a hydrogel in animal studies and demonstrated penetration of buvicaine - a local anesthetic - through the tympanic membrane into the middle ear. Whether the tympanic membrane is inflamed or normal seems to play a role in the penetration ability of the agent used [31] and in which pharmaceutical preparation the administered local anesthetic is present.

In addition, several good quality randomized clinical trials (RCT's) have appeared demonstrating the efficacy of topical treatment for otitis media [63].

The argument that eardrops should not be used because they would make it difficult to assess the eardrum is not valid if one considers that the eardrum should be assessed before eardrops are administered and that the liquid drops can also be allowed to run out again when the patient is lying on his side.

Another argument that is put forward against ear drops in the case of otitis media is that they could enter the middle ear in the case of a perforation of the eardrum and cause a "labyrinth anesthesia" with dizziness. On the one hand, it can be argued that in the case of otitis media there is also a swelling of the mucous membrane, which makes penetration into the inner ear difficult or even impossible [74] and, on the other hand, that in the event of a spontaneous perforation of the eardrum, the pain subsides immediate- ly and therefore no further treatment with analgesic ear drops is necessary. In addition, escaping secretion would prevent penetration into the inner ear.

The use of local anesthetics is already partially recommended for the treatment of otitis media in pediatric practice $[6,8,75]$. This is based on the observation that a rapid reduction in pain can be achieved, whereas antibiotics alone or in combination with systemically administered painkillers such as ibuprofen or paracetamol require much more time to bring about pain relief.

In the meantime, it is assumed that the evidence gap is slowly closing, as the administration of local analgesic drops for otitis media is already cited in various American guidelines and directives [8]. For this the study by Bolt et al. [41] with recommendation grade " $B$ " is quoted [75], which was not yet included in the Cochrane Review in the year 2006 [42]. In the 2012 Cochrane review [72] (weak) evidence was already found when 6 studies were evaluated. In Finland, according to a 2006 study, local anesthetic ear drops were prescribed in $4.4 \%$ of cases with acute otitis media [76].

In 2012, Wood et al. concluded in their review that there was "limited evidence" on the effectiveness of topical pain drops and called for high-quality studies to back this up [44]. In 2014, a review paper [11] concluded the following:

"Topical anesthetic drops compared with placebo: Topical anesthetic drops may be more effective at reducing earache 10 to 30 minutes after administration in children taking paracetamol (lowquality evidence)."

This statement was also adopted by Schilder et al. [64] and - as already stated by Wood et al. [44] - further randomized studies were called for, since clear indications of efficacy were seen on the basis of the studies. All of them emphasize that no side effects have been described $[11,75,76]$.

It should be noted that the studies queried the effect of a single dose on pain. There are no studies (except Hay et al. [48]) that focus on, for example, regular instillation every 30 minutes. Such therapy regimens at least for the first two days of peak pain could have 
a completely different effect. Side effects are not described in any of the existing studies, so that a high therapeutic safety can be assumed even with multiple application.

The positive role of local anaesthetic ear drops as "first line" analgesia is also increasingly seen from the perspective of reduced antibiotic use [66], because good rapid pain relief would help to increase the acceptance of the "wait-and-watch" policy among the children's parents as well [77], as suffering from pain and the associated stress are reduced.

\section{Conclusion}

On the basis of the current literature it is still too early to speak of a "paradigm shift." Nevertheless, in recent years it has been increasingly recognized that analgesic ear drops can provide first-line analgesia in otitis media with relatively short duration of action but rapid onset of action. Thus, analgesic ear drops can contribute to support an antibiotic-saving wait-and-see attitude and still not let the affected children be distressed unnecessarily with ear pain. The demand for further qualifying studies - especially with regard to multiple administration and even more effective galenic preparations - remains.

\section{Acknowledgement}

The article is dedicated to late Prof. Dr. Pierre Federspil who published in 2009 in this journal about topical application of analgesics [59]. It was no longer granted for him to follow the latest developments. He died July $25^{\text {th }}, 2020$.

\section{Conflicts of Interest}

The author declares that there are no economic of personal conflict of interest with the topic of this manuscript. The author has been member of the advisory board and the DMC in the clinical study "SIAXI", "Botulinum toxin in Parkinson's disease" of Merz Pharmaceuticals Germany and USA, and has received lecture fees for continuing education lectures for insurance companies and the Deutsche HNO-Fortbildungsgesellschaft $\mathrm{mbH}$ (German ENT Continuing Education Society) as well as a educating webinar of InfectoPharm Arzneimittel und Consilium GmbH.

\section{References}

[1] Coker TR, Chan LS, Newberry S] et al. Diagnosis, microbial epidemiology, and antibiotic treatment of acute otitis media in children: A systematic review. JAMA 2010; 304: 2161-2169. doi:10.1001/ jama.2010.1651

[2] Kaur R, Morris M, Pichichero ME. Epidemiology of acute otitis media in the postpneumococcal conjugate vaccine era. Pediatrics 2017; 140. doi:10.1542/peds.2017-0181

[3] Rovers MM, Glasziou P, Appelman CL et al. Predictors of pain and/or fever at 3 to 7 days for children with acute otitis media not treated initially with antibiotics: A meta-analysis of individual patient data. Pediatrics 2007; 119: 579-585. doi:/10.1542/peds.2006-2092

[4] Suzuki HG, Dewez JE, Nijman RG et al. Clinical practice guidelines for acute otitis media in children: A systematic review and appraisal of European national guidelines. BMJ open 2020; 10: e035343
[5] Siddiq S, Grainger ]. The diagnosis and management of acute otitis media: American Academy of Pediatrics Guidelines 2013. Archives of Disease in Childhood-Education and Practice 2015; 100: 193-197

[6] Carlens J, Schütz K, Baumann U. Akute Otitis media. Monatsschr Kinderheilkd 2016; 164: 349-358. doi:10.1007/s00112-016-0082-2

[7] Arbeitsgemeinschaft der Wissenschaftlichen Medizinischen Fachgesellschaften e.V. Ohrenschmerzen, Stand: 30.09.2020

[8] Lieberthal AS, Carroll AE, Chonmaitree T et al. From the American Academy of Pediatrics: The diagnosis and management of acute otitis media. Pediatrics 2013; 131: e964-e999. doi:10.1542/peds.20123488

[9] Grevers G. Challenges in reducing the burden of otitis media disease: an ENT perspective on improving management and prospects for prevention. Int J Pediatr Otorhinolaryngol 2010; 74: 572-577. doi:10.1016/j.ijporl.2010.03.049

[10] Lautermann ], Begall K, Hilger G et al. Leitlinie „Seromukotympanum “-Langfassung. HNO 2012; 60: 540-544

[11] Venekamp RP, Damoiseaux RA, Schilder AG. Acute otitis media in children. BMJ clinical evidence 2014; 2014: 0301

[12] Paulsen F. Muzine auf dem Gebiet der HNO-Heilkunde. HNO 2002; 50 : 209-216

[13] Buzatto G, Tamashiro E, Proenca-Modena J et al. The pathogens profile in children with otitis media with effusion and adenoid hypertrophy. PLoS One 2017; 12: e0171049

[14] Thomas JP, Berner R, Zahnert T et al. Strukturiertes Vorgehen bei akuter Otitis media. Dtsch Arztebl Int 2014; 111: 151-160. doi:10.3238/arztebl.2014.0151

[15] Linck A. „Otalgan” und andere Illusionen und Irrtümer in der Therapie der Oto-Rhino-Laryngologie. Archiv für Ohren-, Nasen-und Kehlkopfheilkunde 1938; 145: 216-230

[16] Breuninger H. Sinn und Unsinn der Anwendung von Ohrtropfen. Laryngologie, Rhinologie, Otologie und ihre Grenzgebiete 1983; 62: 280-283. doi:10.1055/s-2007-1008432

[17] Uddman R, Grunditz T, Larsson A et al. Sensory innervation of the ear drum and middle-ear mucosa: Retrograde tracing and immunocytochemistry. Cell Tissue Res 1988; 252: 141-146

[18] Ullrich D, Aurbach G, Drobik C. A prospective study of hyperlipidemia as a pathogenic factor in sudden hearing loss. Eur Arch Otorhinolaryngol 1992; 249: 273-276. doi:10.1007/BF00714491

[19] Reiß M. Facharztwissen HNO-Heilkunde: Differenzierte Diagnostik und Therapie. Springer Science \& Business Media; 2009

[20] Rosen S. The tympanic plexus: an anatomic study. Arch Otolaryngol 1950; 52: 15-18. doi:10.1001/archotol.1950.00700030034003

[21] Nagai T, Nagai M, Nagata $Y$ et al. The effects of anesthesia of the tympanic membrane on eustachian tube function. Archives of Oto-rhino-laryngology 1989; 246: 210-212. doi:10.1007/BF00453664

[22] Costen JB, Clare MH, Bishop GH. The transmission of pain impulses via the chorda tympani nerve. Annals of Otology, Rhinology \& Laryngology 1951; 60: 591-609

[23] Saunders R, Weider D. Tympanic membrane sensation. Brain: A journal of Neurology 1985; 108: 387. doi:10.1093/brain/108.2.387

[24] Rockley T, Hawke W. The middle ear as a baroreceptor. Acta Otolaryngol (Stockh) 1992; 112: 816-823. doi:10.3109/00016489209137479

[25] Hoskison E, Daniel M, Al-Zahid S et al. Drug delivery to the ear. Therapeutic delivery 2013; 4: 115-124. doi:10.4155/tde.12.130

[26] Schmidt S, Hellström S. Phenol anesthesia of the tympanic membrane in purulent otitis media: a structural analysis in the rat. Eur Arch Otorhinolaryngol 1993; 249: 470-472. doi:10.1288/00005537197802000-00010

[27] Blessing R, Schlenter W. Oberflächenanästhesie des Trommelfells mit DMSO und Lokalanästhetika. Laryngo-Rhino-Otologie 1990; 69: 285-288. doi:10.1055/s-2007-998191 
[28] Hoberman A, Paradise JL, Reynolds EA et al. Efficacy of Auralgan for treating ear pain in children with acute otitis media. Archives of Pediatrics \& Adolescent Medicine 1997; 151: 675-678

[29] Uhde G. The problem of permeability and anesthesia of the tympanic membrane. AMA Archives of Otolaryngology 1957; 66: 391-407. doi:10.1001/archotol.1957.03830280021004

[30] Abramson M. Topical anesthesia of the tympanic membrane. Arch Otolaryngol 1969; 90: 147-149

[31] Møller Å, Grøntved A. Topical anaesthesia of the normal tympanic membrane: a controlled clinical trial of different suspensions of lidocaine. ORL 1990; 52: 168-173

[32] Rahm W, Strother W, Gulick W et al. LXX The Effects of Anesthetics upon the Ear II. Procaine Hydrochloride. Annals of Otology, Rhinology \& Laryngology 1960; 69: 969-975. doi:10.1177/000348946006900402

[33] Wada S-I, Starr A. Generation of auditory brain stem responses (ABRs). I. Effects of injection of a local anesthetic (procaine $\mathrm{HCl}$ ) into the trapezoid body of guinea pigs and cat. Electroencephalogr Clin Neurophysiol 1983; 56: 326-339

[34] Kasaba T, Onizuka S, Takasaki M. Procaine and mepivacaine have less toxicity in vitro than other clinically used local anesthetics. Anesthesia \& Analgesia 2003; 97: 85-90.

[35] Khanal S, Modi R, Akhtar K et al. Benzocaine-Associated Methemoglobinemia. Am J Ther 2018; 25: e771-e772

[36] Guay J. Methemoglobinemia related to local anesthetics: a summary of 242 episodes. Anesthesia \& Analgesia 2009; 108: 837-845

[37] Schmidt RM, Rosenkranz HS. Antimicrobial activity of local anesthetics: lidocaine and procaine. The Journal of Infectious Diseases 1970; 597-607

[38] Mühlenfeld H-M, Saal K. Die neue DEGAM-Leitlinie Nr. 7 „Ohrenschmerzen”. ZFA-Zeitschrift für Allgemeinmedizin 2005; 81: 544-549

[39] Francois M. Efficacité et tolérance d'une application locale de phénazone et de chlorhydrate de lidocaïne (Otipax) dans les otites congestives du nourrisson et de l'enfant. Ann Pediatr (Paris) 1993; 40: 481-484

[40] Deutsche Gesellschaft für Hals-Nasen-Ohren-Heilkunde - Kopf- und Hals-Chirurgie e. V. S2K-Leitlinie Antibiotikatherapie bei HNO-Infektionen. In: Düsseldorf: AWMF 2019;

[41] Bolt P, Barnett P, Babl FE et al. Topical lignocaine for pain relief in acute otitis media: results of a double-blind placebo-controlled randomised trial. Arch Dis Child 2008; 93: 40-44

[42] Foxlee R, Johansson AC, Wejfalk J et al. Topical analgesia for acute otitis media (with update 11 feb 2011). Cochrane Database Syst Rev 2006

[43] AAP/AAFP. American Academy of Pediatrics, American Academy ol Family Physicians, clinical practical guideline. Subcommittee on Management of Acute Otitis Media. Diagnosis and Management of Acute Otitis Media. Pediatrics 2013; 131: e964-e999

[44] Wood DN, Nakas N, Gregory CW. Clinical trials assessing ototopical agents in the treatment of pain associated with acute otitis media in children. Int | Pediatr Otorhinolaryngol 2012; 76: 1229-1235. doi:10.1016/j.jporl.2012.05.022

[45] Laine MK, Tähtinen PA, Ruuskanen O et al. Symptoms or symptombased scores cannot predict acute otitis media at otitis-prone age. Pediatrics 2010; 125: e1154-e1161. doi:10.1542/peds.2009-2689

[46] Thompson M, Vodicka TA, Blair PS et al. Duration of symptoms of respiratory tract infections in children: Systematic review. Bmj 2013; 347: $f 7027$

[47] Glasziou PP, Del Mar CB, Sanders SL et al. Antibiotics for acute otitis media in children. Cochrane Database Syst Rev 2004, doi:10.1002/14651858.CD000219.pub2: Cd000219

[48] Hay AD, Downing H, Francis NA et al. Anaesthetic-analgesic ear drops to reduce antibiotic consumption in children with acute otitis media: the CEDAR RCT. Health Technology Assessment 2019; 23. doi:10.3310/hta23340
[49] Hoberman A, Paradise JL, Rockette HE et al. Treatment of acute otitis media in children under 2 years of age. $N$ Engl J Med 2011; 364: 105-115

[50] Spiro DM, Tay K-Y, Arnold DH et al. Wait-and-see prescription for the treatment of acute otitis media: a randomized controlled trial. JAMA 2006; 296: 1235-1241. doi:10.1001/jama.296.10.1235

[51] Venekamp RP, Burton M], van Dongen TM et al. Antibiotics for otitis media with effusion in children. Cochrane Database Syst Rev 2016; doi:10.1002/14651858.CD009163.pub3

[52] Bertin L, Pons G, d'Athis P et al. A randomized, double-blind, multicentre controlled trial of ibuprofen versus acetaminophen and placebo for symptoms of acute otitis media in children. Fundamental \& clinical pharmacology 1996; 10: 387-392. doi:10.1111/j.1472-8206.1996. tb00590.x

[53] Graham GG, Davies M], Day RO et al. The modern pharmacology of paracetamol: therapeutic actions, mechanism of action, metabolism, toxicity and recent pharmacological findings. Inflammopharmacology 2013; 21: 201-232

[54] Hay AD, Costelloe C, Redmond NM et al. Paracetamol plus ibuprofen for the treatment of fever in children (PITCH): randomised controlled trial. Bmj 2008; 337. doi:10.1136/bmj.a1302

[55] Sjoukes A, Venekamp RP, van de Pol AC et al. Paracetamol (acetaminophen) or non-steroidal anti-inflammatory drugs, alone or combined, for pain relief in acute otitis media in children. Cochrane Database Syst Rev 2016; doi:10.1542/peds.2012-3488

[56] Sarrell EM, Mandelberg A, Cohen HA. Efficacy of naturopathic extracts in the management of ear pain associated with acute otitis media. Archives of pediatrics \& adolescent medicine 2001; 155: 796-799. doi:10.1001/archpedi.155.7.796

[57] Sarrell EM, Cohen HA, Kahan E. Naturopathic treatment for ear pain in children. Pediatrics 2003; 111: e574-e579

[58] Walson P, Wason S, McClain T et al. Double-blind, placebo-controlled comparison of Auralgan and Americaine for the treatment of otalgia associated with Otitis Media in children. Clinical Pharmacology \& Therapeutics 2004; 75: P74-P74. doi:10.1016/j.clpt.2003.11.280

[59] Adam D, Federspil P, Lukes $M$ et al. Therapeutic properties and tolerance of procaine and phenazone containing ear drops in infants and very young children. Arzneimittelforschung 2009; 59: 504-512

[60] Schwedt G. Einführung in die Pharmazeutische Chemie. Springer 2019

[61] Wright S. Topical aqueous $2 \%$ lignocaine eardrops reduced ear pain in children with acute otitis mediaCommentary. Evid Based Nurs 2008; 11: 107-107. doi:10.1136/ebn.11.4.107

[62] Thornton K, Parrish F, Swords C. Topical vs. systemic treatments for acute otitis media. Pediatr Nurs 2011; 37: 263

[63] Teschner M. Evidenz und Evidenzlücken zur Behandlung der gestörten Mittelohrbelüftung sowie der Otitis media. Laryngo-Rhino-Otologie 2016; 95: S136-S154. doi:10.1055/s-0041-108952

[64] Schilder AG, Marom T, Bhutta MF et al. Panel 7: otitis media: treatment and complications. Otolaryngology-Head and Neck Surgery 2017; 156: S88-S105

[65] Rosa-Olivares ], Porro A, Rodriguez-Varela M et al. doi:10.1542/ pir.36-11-480

[66] Vergison A, Dagan R, Arguedas A et al. Otitis media and its consequences: beyond the earache. The Lancet infectious diseases 2010; 10 : 195-203

[67] Michel O. Zertifizierte Fortbildung: Lokalanästhetika in der HNOHeilkunde. HNO-Nachrichten 2011; 41: 41-45

[68] Michel O. Otitis externa gezielt behandeln. HNO Nachrichten 2017; 47: 38-45

[69] Michel O. [External otitis and otitis media: diagnostics and treatment]. MMW Fortschritte der Medizin 2010; 152: 38-42 
[70] Mösges R, Kaatz V, Schmalz P et al. Glycerol lidocaine eardrops for the treatment of acute abacterial otitis externa. Arzneimittelforschung 2010; 60: 427-431

[71] Ersner MS, Saltzman M. XLIV Ear Drops in Acute Otitis Media: An Evaluation of Various Medicaments and an Analysis of the Untoward Effects of Antipyrine and Benzopyrine. Annals of Otology, Rhinology \& Laryngology 1942; 51: 471-475. doi:10.1177/000348944205100217

[72] Oleszczuk M, Fernandes RM, Thomson D et al. The Cochrane Library and acute otitis media in children: an overview of reviews. EvidenceBased Child Health: A Cochrane Review Journal 2012; 7: 393-402. doi:10.1002/ebch.1839

[73] Yang R, Saarinen R, Okonkwo OS et al. Transtympanic delivery of local anesthetics for pain in acute otitis media. Mol Pharm 2019; 16: $1555-1562$
[74] Matthias R, Handrock M. Zur Wirkung ototoxischer Substanzen bei intratympanaler Applikation. Archives of Oto-rhino-laryngology 1980; 227: 417-420. doi:10.1007/BF00467544

[75] Prasad S, Ewigman B. Use anesthetic drops to relieve acute otitis media pain. The Journal of Family Practice 2008; 57: 370

[76] Pulkki ], Huikko S, Rautakorpi U-M et al. Management of pain in acute otitis media in Finnish primary care. Scand J Infect Dis 2006; 38: 265-267. doi:10.1080/00365540500434679

[77] Van Uum RT, Venekamp RP, Schilder AG et al. Pain management in acute otitis media: A qualitative study of parents' views and expectations. BMC family practice 2019; 20: 18 . doi:10.1186/ s12875-019-0908-9 